\title{
Liquid chromatography-high resolution mass spectrometry (LC-HRMS) analysis of Auxin Metabolites in Arabidopsis thaliana shoot tissues
}

Prasad Phapale ( $\sim$ prasad.phapale@embl.de)

EMBL Metabolomics Core Facility, Heidelberg, Germany

Theodore Alexandrov

EMBL Metabolomics Core Facility, Heidelberg, Germany

\section{Method Article}

Keywords: Indole acetate, plant harmones, auxins, metabolomics, LC-MS/MS, HRMS, mass spectrometry

Posted Date: August 22nd, 2019

DOI: https://doi.org/10.21203/rs.2.1829/v1

License: (c) (1) This work is licensed under a Creative Commons Attribution 4.0 International License.

Read Full License 


\section{Abstract}

Auxin metabolome affects almost every facet of plant development from hormone transport and biosynthesis to degradation. It also triggers several environmental responses. Measuring auxin biosynthesis can enable a better understanding of metabolism and hormonal activities during plant growth and developmental phases. Here we optimised a solid phase extraction (SPE) sample preparation and liquid chromatography-high resolution mass spectrometry \(LC-HRMS) method for profiling auxin metabolites in the tissues $\backslash$ (shoot and leaves) of the model plant system (Arabidopsis thaliana). We combined a sensitivity SPE sample preparation protocol with accurate LC-HRMS analysis to profile auxin metabolites in plant tissues.

\section{Introduction}

Measurements of auxin metabolites at steady state as well as their metabolic flux can be of great importance to understand hormonal regulation of plant metabolism. The increasing use of LC-HRMS analysis in plant metabolomic analysis made specific and sensitive measurements of several metabolites possible. The HRMS analysis unlike triple quadruple methods required less method development and is more accurate and robust. So far there are several reports on analysis of indole acetate pathway using LC-triple quadruple MS or GC-MS instruments but very few reports on use of LCHRMS.

Also, sensitivity of such analysis is hampered by methanol extraction protocols due to high matrix effect from plant tissues. Here, we optimised SPE sample extraction protocol for plant tissues to improve sensitivity and combined with accurate LC-HRMS analysis. The reported method is simple, robust, sensitive and accurate for the determination of auxin metabolites in Arabidopsis thaliana shoot tissues.

\section{Reagents}

MS grade Methanol (Biosolve BV, The Netherlands),

MilliQ Water

13C internal standards were purchased from OlChemim s.r.o. (https://www.olchemim.cz/Products.aspx? idc $=2 \&$ idp $=9$ )

Extraction buffer: (50 mM sodium phosphate buffer, $\mathrm{pH} 7.0$, containing $0.1 \%$ diethyldithiocarbamate)

Loading buffer: Use $1 \mathrm{ml}$ of the extraction buffer to test the amount of $1 \mathrm{M} \mathrm{HCl}$ needed for its acidification to $\mathrm{pH}$ 2.7. Prepare the loading buffer by adding twice the amount of $1 \mathrm{M} \mathrm{HCl}$ per milliliter of extraction buffer. (Addition of $0.5 \mathrm{ml}$ sample extract to $0.5 \mathrm{ml}$ loading buffer must give a $\mathrm{pH}$ 2.7.)

Note: Keep diluents in chilled condition $\left(0-4^{\circ} \mathrm{C}\right)$ 


\section{Equipment}

MM301 bead mill (Retsch GmbH (http://www.retsch.com))

Oasis HLB 1 cc Vac Cartridge, 30 mg Cartridge Sorbent (Waters; Catalogue number: 186003908)

Visiprep $^{\text {TM }}$ 12- and 24- Port Vacuum Manifold (Sigma Aldrich)

High resolution mass spectrometry (Q Exactive Plus MS, Thermo Scientific)

Agilent 1260 liquid chromatography (LC) system

LC column Kinetex C18 (100X 2.1; 2.6uM)

Eppendrof Concentrator plus

MICROVAP Microplate Evaporator (Catalog \# 11801)

\section{Procedure}

\section{Sample preparation and metabolite extraction:}

Sample Extraction (For Indole acetate metabolites; IAA): 20 to $50 \mathrm{mg}$ of tissues was mixed with $1 \mathrm{ml}$ cold extraction buffer and homogenised using a Mixer Mill MM301 bead mill at a frequency of $25 \mathrm{~Hz}$ for $5 \mathrm{~min}$ after adding $2 \mathrm{~mm}$ ceria-stabilised zirconium oxide beads. Add $1 \mu \mathrm{g}$ of ${ }^{13} \mathrm{C}$ indole acetate (or other suitable internal standards) and vortex well. Incubated this plant extracts at $4^{\circ} \mathrm{C}$ with continuous shaking (20 min) and centrifuge ( $15 \mathrm{~min}, 23000 \mathrm{~g}$ at $\left.4^{\circ} \mathrm{C}\right)$. Transfer the supernatant to a new vial and adjust $\mathrm{pH}$ to 2.7 with $1 \mathrm{M} \mathrm{HCl}$

SPE procedure:

a. Prepare SPE vacuum assembly with HLB (30mg) column cartridges.

b. Condition SPE column with $1 \mathrm{~mL}$ of methanol and $1 \mathrm{~mL}$ of water

c. Equilibrate the column with $250 \mu \mathrm{l}$ of $5 \mathrm{mM} \mathrm{HCl}$. (Do not let column dry)

d. Load Equilibrate column with $0.5 \mathrm{ml}$ loading buffer

e. Load $0.5 \mathrm{ml}$ Sample onto the SPE column, and mix intensely with the loading buffer. Pass the mixture slowly through the HLB sorbent immediately. 
f. Wash the column with $2 \mathrm{ml}$ of $5 \%$ methanol.

g. Put clean glass tubes into the manifold rack, and then elute the sample from the column with $2 \mathrm{ml}$ of $80 \%$ methanol.

h. Collect sample eluent and evaporate the samples to dryness in a SpeedVac concentrator or under nitrogen stream at room temperature.

6. Store samples at $-80^{\circ} \mathrm{C}$ till further analysis or ship in dry ice.

7. Sample are reconstituted in mobile phase (or $50 \%$ methanol) before analysis

8. Processed Blank sample was prepared in the same manner as above where sample tissue is replaced with $50 \mathrm{uL}$ of buffer

9. Pooled QC sample: equal mix of all samples prepared after processing

\section{LC-HRMS analysis}

\section{LC conditions:}

Column: Kinetex C18 (100X 2.1; 2.6uM) at temperature $40^{\circ} \mathrm{C}$

Mobile phase A: $0.1 \%$ acetic acid in Water

Mobile phase B: $0.1 \%$ acetic acid in Methanol

Flow rate: $0.26 \mathrm{ml} / \mathrm{min}$

Mobile phase Gradient:

Time/ \%B: 0/5, 3/ 5, 10/75, 12/98, 16/98, 16.1/5, 19/5

Injection volume: $10 \mathrm{uL}$

\section{MS parameters:}

ESI mode: Positive

Spray voltage $4.5 \mathrm{eV}$ 
Capillary Temp $300^{\circ} \mathrm{C}$

Probe Heater Temp $300^{\circ} \mathrm{C}$

Sheath Gas: 30 and Auxiliary Gas: 5 units

S-Lens RF Level 65v

$\mathrm{m} / \mathrm{z}$ range: 60 to 900

\section{Analysis sequence:}

1. Mobile phase (A:B; 90:10) blank: to check the background from LC column and LC-MS system

2. Processed Blank: to check the contamination and background from sample processing

3. Auxin standard mix: for the system suitability of the method

3. Pooled QC: 5 injections or till the LC-MS system gets stabilised

4. Plant tissue samples

5. Inject Pooled QC after each 6 tissue samples

6. Blank

7. Auxin standard mix: for the system suitability of the method

\section{Data analysis:}

Thermo Xcalibur Quan software used for extracting peaks (as extracted ion chromatograms; EIC) for the metabolites of interest based on HRMS data with $5 \mathrm{ppm}$ window for $\mathrm{M}+\mathrm{H}$ adducts. The peaks were identified based on exact $\mathrm{m} / \mathrm{z}$ and retention times in comparison with authentic standards. The peaks areas were used for relative quantification in the samples.

Targeted metabolites; chemical formulas:

Tryptophan; $\mathrm{C} 11 \mathrm{H} 12 \mathrm{~N} 2 \mathrm{O} 2$

Indole-3-acetaldoxime; $\mathrm{C} 10 \mathrm{H} 10 \mathrm{~N} 2 \mathrm{O}$

Indole-3-acetonitrile; $\mathrm{C} 10 \mathrm{H} 8 \mathrm{~N} 2$ 
Indole-3-acetamide; $\mathrm{C} 10 \mathrm{H} 10 \mathrm{~N} 2 \mathrm{O}$

Indole-3-acetic acid; C10H9NO2

Indole glucosinolate; C16H19N2O9S2

Indole-3-pyruvic acid; C11H9NO3

The MS/MS data for above metabolites can be downloaded from EMBL-MCF spectral library http://curatr.mcf.embl.de/MS2/

\section{Troubleshooting}

SPE Sample prep:

1. Early elution of metabolites during loading or washing step: make sure to have sample in 100 aqueous conditions with $\mathrm{pH}$ adjusted to acidic side as mentioned in protocol.

2. Verify SPE loading, wash and elution conditions using auxin metabolite standard mixtures.

\section{Time Taken}

\section{For 10 samples:}

Mobile phase Reagent preparations: $1 \mathrm{hr}$

Sample preparation: $30 \mathrm{~min}$

LC-MS set-up and stabilisation: $1 \mathrm{hr}$

LC-MS run time: $20 \mathrm{~min}$

Data analysis: $1-2 \mathrm{hrs}$

\section{Anticipated Results}

The representative chromatograms from standards is shown in Figure 1.

The \%CV for QC and ${ }^{13} \mathrm{C}$ internal standard should be more than $10 \%$. 


\section{References}

1. Novak, O., Pencık, A., Blahousek, O., and Ljung, K (2016), Quantitative auxin metabolite profiling using stable isotope dilution UHPLC-MS/MS. Curr. Protoc. Plant Biol. 1:419-430. doi: 10.1002/cppb.20028

2. Palmer A1, Phapale P1, Fay D1, Alexandrov T (2018) Curatr: a web application for creating, curating and sharing a mass spectral library. Bioinformatics. 15;34(8):1436-1438. doi:

10.1093/bioinformatics/btx786

\section{Acknowledgements}

We thank all the EMBL core facilities and Alexandrov team for providing necessary support.

We thank Heisler group member Dr. Hasthi Ram for providing plant tissue.

\section{Figures}

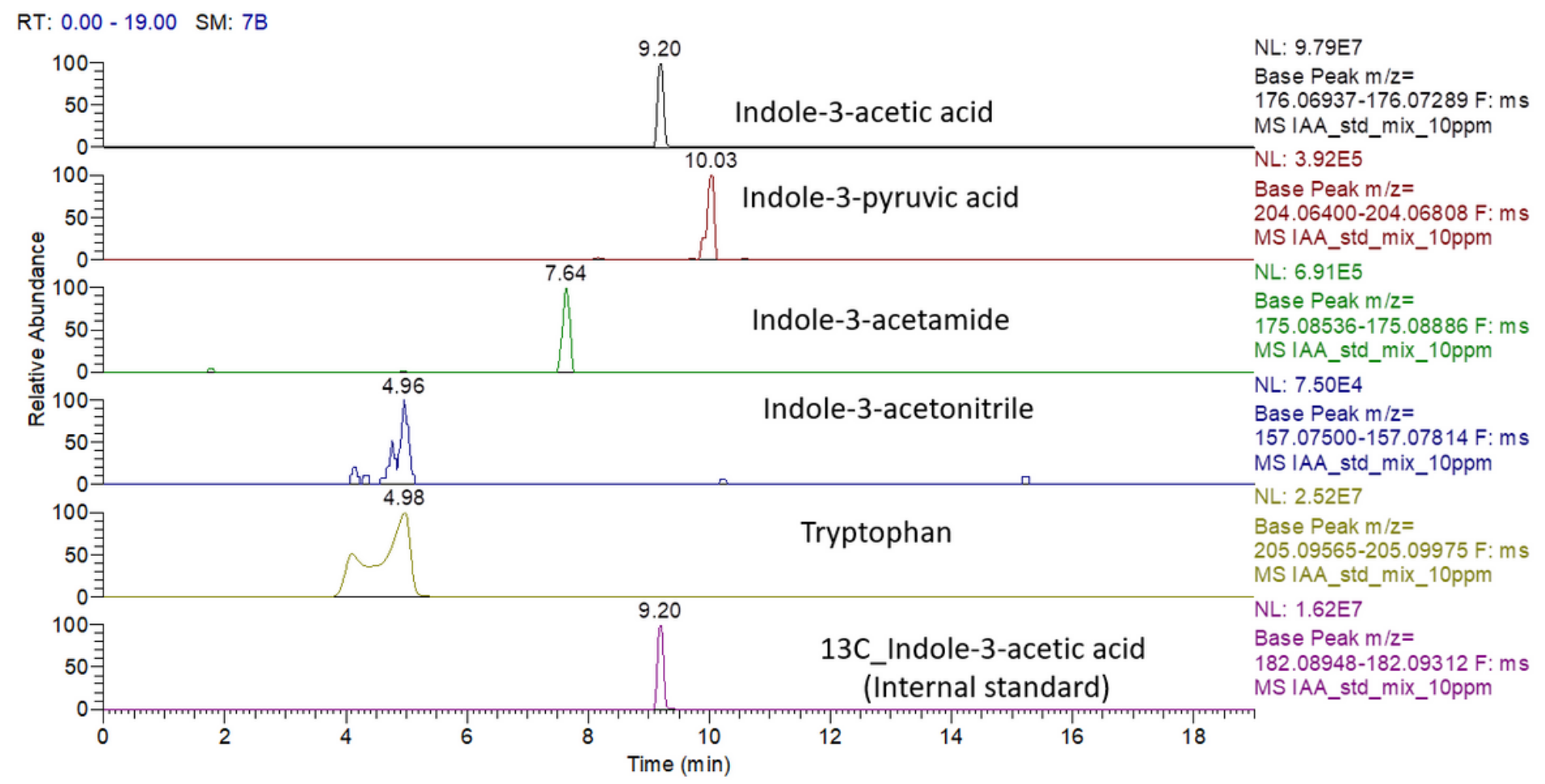

Figure 1 
The representative extracted ion chromatograms (10 ppm window) from the analysis of standards. 